\begin{tabular}{lllllll} 
O P E R A T I O N S R E S E A R C H A N D D E C I S I O N S \\
\hline No. 1
\end{tabular}

DOI: $10.37190 /$ ord210102

\title{
A COMPOSITIONAL APPROACH TO TWO-STAGE DATA ENVELOPMENT ANALYSIS IN INTUITIONISTIC FUZZY ENVIRONMENT
}

\author{
NAFISEH JAVAHERIAN ${ }^{1}$, ALI HAMZEHEE ${ }^{1 *}$, HOSSEIN SAYYADI TOORANLOO ${ }^{2}$ \\ ${ }^{1}$ Department of Applied Mathematics, Kerman Branch, Islamic Azad University, Kerman, Iran \\ ${ }^{2}$ Department of Management, Meybod University, Meybod, Iran
}

\begin{abstract}
Classical methods of data envelopment analysis operate by measuring the efficiency of decision-making units (DMUs) compared to similar units, without taking their internal structure into account. However, some $D M U$ s consist of two stages, with the first stage producing an intermediate product, which is then consumed in the second stage to produce the final output. The efficiency of this type of $D M U$ is often measured using two-stage network data envelopment analysis. In real world, most data are vague. Therefore, the inputs and outputs of systems with vagueness data create uncertainty challenges for $D M U$ s. As a result, when uncertainty appears, intuitionistic fuzzy sets can show more information than classical fuzzy sets. This paper presents a model of two-stage Network Data Envelopment Analysis based on intuitionistic fuzzy data, which measures the efficiency of the first and second stages of each $D M U$, and the overall efficiency measures based on the stage efficiencies.
\end{abstract}

Keywords: data envelopment analysis, intuitionistic fuzzy, two-stage DEA, triangular numbers

\section{Introduction}

Data Envelopment Analysis (DEA) is widely used as a powerful method for evaluating and comparing the performance of a series of options or decision-making units $(D M U s)$. This method involves using the available information about the entities being evaluated for the experimental estimation of an efficient frontier that envelopes all the available data, hence the name DEA [2]. First proposed by Charnes et al. [8], DEA belongs to the family of non-parametric methods based on linear programming. In general, the foundation of non-parametric efficiency evaluation methods was laid by Farrell [21], who used a purely mathematical approach to develop a new performance measurement

${ }^{*}$ Corresponding author, email address: hamzehee ali@yahoo.com

Received 26 July 2020, accepted 26 February 2021 
method opposite to the existing parametric methods [5]. In some cases, the internal structure of $D M U \mathrm{~s}$ is of great importance for performance evaluation and offers critical information that needs to be carefully considered in the evaluation process to avoid imprecise and incomprehensible results. Network data envelopment analysis (NDEA) is an extension of traditional DEA that seeks to incorporate the internal structure of DMUs into its decision models. The first studies in this field were carried out in 1996 by Fare and Grosskopf [18].

Then, Fare and Grosskopf [19] searched the reason for NDEA expression and its significance in 2000. In the following years, Cook et al. [14] classified NDEA models into four categories. This category includes: 1) standard DEA approach; in this field, we can refer to the articles of Lewis and Sexton [31], Chilingerian and Sherman [13], Castelli [7] who evaluated the efficiency of $D M U$ s by considering the internal structures. 2) game theory approach; the Stackelberg game concept is a non-contribution approach used for the first time by Liang et al. $[32,33]$ to measure the performance of supply chain settings. Then, Li et al. [34] used the approach of Liang et al. [33] to calculate the efficiency of their research process. 3) NDEA approach; researchers such as Chen and Zhu [11] and Chen et al. [12] developed the NDEA model under variable returns to scale (VRS) assumption to evaluate the performance of linear and non-linear models. Tone and Tsutsui [49] also expressed the network SBM method. 4) decomposition efficiency approach; in this approach, efficiency is studied by considering the series and parallel structures of the units. Kao and Hwang [24, 25] introduced a series NDEA model and described the efficiency of the overall system as a product of the efficiency of the subunits. Kao [26] developed a parallel NDEA model, which is capable to calculate the efficiency of the system and the subunits of each $D M U$ in linear programming. Kao [27] also presented a full ranking of studies in NDEA based on the type of network structure that in addition to the aforementioned classification introduced seven categories for NDEA: 1) basic two-stage structures, 2) general two-stage structures, 3) series structures, 4) parallel structures, 5) mixed structures, 6) hierarchical structure, 7) dynamic structures. These models were developed by several researchers in later years.

The two-stage DEA can be considered the most basic form of NDEA. Many of the methods developed for solving complex NDEA models are inspired by the methods formulated for solving simpler two-stage DEA models. Over the years, researchers proposed various methods for evaluating the efficiency of $D M U$ s in two-stage DEA models. These methods are reviewed in the articles by Cook et al. [14], Maghbouli et al. [40], Lim and Zhu [36], Emrouznejad and Yang [17], and Liu et al. [38]. In traditional DEA, the use of imprecise data about $D M U$ s can severely undermine the accuracy of the results. By formalising uncertainty in decision making with the help of fuzzy logic, DEA can be modified to properly process such data. Although Zadeh [53] was the first to propose using fuzzy logic in DEA, the seminal article on this subject was written by Sengupta [45]. Since then, numerous articles have been published in this field. A review of these works 
can be found in the article published by Emrouznejad and Yang [17]. Triantis and Girod [50] proposed a mathematical programming model that operates by converting fuzzy inputs and outputs to crisp (non-fuzzy) numbers based on membership function values. Guo and Tanaka [23] developed a fuzzy DEA (FDEA) model with the CCR approach, in which fuzzy constraints are converted to crisp constraints by defining a production possibility surface and comparison rule for fuzzy numbers. Later, Leon et al. [30] used the approach of Guo and Tanaka [23] to develop an FDEA model with the BCC approach. Saati and Memarian [44] introduced an FDEA method in which all DMUs are evaluated by a set of common weights at different alpha levels. Nosrat et al. [42] used the reliability theory to evaluate fuzzy $D M U$ s. Wang et al. [51] used the concept of alpha value to define the FDEA models as interval numbers.

Although many studies have been done in the field of FDEA, few methods proposed to solve fuzzy NDEA (FNDEA) models, which each of them have its limitations. First, Kao and Liu [29], used fuzzy L-R numbers, developed the lower and upper bounds for the efficiency of $D M U$ for each alpha cut in a two-stage fuzzy multiplicative DEA model. Lozano [39] proposed two models for evaluating the changes of the stage efficiencies obtained by Kao and Liu [29] methods. Tavana and Khalil Damghani [48] used trapezoidal fuzzy numbers in the Kao and Liu method [29] to transform the initial nonlinear model into a linear model that was no longer dependent on the alpha variable. In another study, Liu [37] developed the proposed Kao and Liu method [29] for fuzzy finite regions. All of these methods are inspired by Kao and Liu [29]. Although this method has been widely used it does not work when the inputs and outputs are non-normal fuzzy. In this method, the upper and lower bounds are obtained for the efficiency of the units, whereas these obtained bounds cannot directly compare and rank the DMUs. So Kao and Liu [28] used the presented index in Chen's paper [10] combined these bounds and finally ranked the $D M U$ s. But in all these methods, the proposed models for calculating the lower boundaries are non-linear and just work in constant returns to scale (CRS) assumptions. In another paper presented by Shureshjani and Foroughi [47], deducted the limitation of Kao and Liu method [29] and used it for two-stage DEA in both CRS and VRS. In this method, by using the conversion function $Q_{\infty}$, two-stage DEA models are transformed into parametric linear programming models, and as a result, the efficiency scores of the obtained $D M U$ s from these models are the functions of the alpha parameter that depends on alpha cuts. The main advantages of using intuitionistic fuzzy network DEA (IFNDEA) instead of FNDEA is the complexity of choosing FNDEA approaches because they are not easily generalisable to IFNDEA model.

In some cases, there may be some ambiguity in the decision-making team's assessment of a fuzzy criterion. In such cases, where the information is too ambiguous or insufficient for decision making, it is best to avoid Zimmerman's fuzzy sets theory [54] and instead use the intuitionistic fuzzy sets (IFS) theory. Intuitionistic fuzzy data have been used in the studies of Boran et al. [6], Li et al. [35], Daneshvar [15], and Wei et al. 
[52], among others. Puri and Yadav [43] developed an intuitionistic fuzzy DEA (IFDEA) model for the banking sector in India. Ameri et al. [1] has developed a self-assessment model of NDEA in the intuitionistic fuzzy environment to measure the efficiency of the parallel system when some inputs and outputs are intuitionistic fuzzy in nature. Thus, all the variables of the proposed model in this study, including inputs and outputs and intermediates and weights are intuitionistic fuzzy numbers and can easily evaluated by expected valued function as the variables in Ameri et al. [1] are not all intuitionistic fuzzy numbers. So, the proposed model can show the ability of the method in real world accurately. Another study in the IFDEA field published by Shakouri et al. [46]. They used the NDEA model in series and parallel structures. Then, by introducing the accuracy function, they transformed the model into a crisp linear programming and ranked and evaluated the decision-making units based on the definition of alpha cut and degree of hesitation. The proposed two-stage model of this study compared with the model of Shakouri et al. [46] has more powerful and application in the real world due to all the variable are intuitionistic fuzzy. So, because of the intuitionistic fuzzy environment and the two-stage of the model, the overall $D M U$ s and each of the stages are separable and rankable which caused a unique advantage of the proposed model over the other models.

The goal of the present study was to design a mathematical formulation for two-stage IFDEA models, such that the resulting models offer a more realistic and practical assessment of efficiency without the weaknesses of the previous models. Hence, this paper proposed IFNDEA by all intuitionistic fuzzy variable.

\section{Preliminaries}

\subsection{Intuitionistic fuzzy sets}

Intuitionistic fuzzy sets [53] can be seen as a generalisation of the classic fuzzy sets first introduced by Atanassov [4]. Atanassov defines IFS as $\tilde{A}^{I}$ in $X$ with form

$$
\tilde{A}^{I}=\left\{\prec x, \mu_{\tilde{A}^{I}}(x), v_{\tilde{A}^{I}}(x) \succ, \forall x \in X\right\}
$$

where

$$
\mu_{\tilde{A}^{I}}(x): X \rightarrow[0,1], v_{\tilde{A}^{I}}(x): X \rightarrow[0,1]
$$

such that 


$$
0 \leq \mu_{\tilde{A}^{I}}(x)+v_{\tilde{A}^{I}}(x) \leq 1, \forall x \in X
$$

where $\mu_{\tilde{A}^{I}}(x)$ and $v_{\tilde{A}^{I}}(x)$ denote the degree of membership and the degree of non-membership of the element $x \in X$ to the set $\tilde{A}^{I}$, respectively. Besides, for each $x \in X$, intuitionistic index or the hesitancy degree of $x, \pi_{x}$, is defined as $\pi_{x}=1-\mu_{\tilde{A}^{I}}(x)-v_{\tilde{A}^{I}}(x)$.

\subsubsection{Intuitionistic fuzzy number}

Definition 1 [41]. $\tilde{A}^{I}$ is said to be an intuitionistic fuzzy number (IFN), if:

1) It is normal, i.e., $\forall x_{\circ} \in X: \mu_{\tilde{A}^{I}}\left(x_{\circ}\right)=1, v_{\tilde{A}^{I}}\left(x_{\circ}\right)=0$.

2) $\mu_{\tilde{A}^{I}}(x)$ is convex, i.e.,

$$
\mu_{\tilde{A}^{I}}\left(\lambda x_{1}+(1-\lambda) x_{2}\right) \geq \min \left\{\mu_{\tilde{A}^{I}}\left(x_{1}\right), \mu_{\tilde{A}^{I}}\left(x_{2}\right)\right\}, \forall x_{1}, x_{2} \in X, \lambda \in[0,1]
$$

3) $v_{\tilde{A}^{I}}(x)$ is concave, i.e.,

$$
v_{\tilde{A}^{I}}\left(\lambda x_{1}+(1-\lambda) x_{2}\right) \leq \max \left\{v_{\tilde{A}^{I}}\left(x_{1}\right), v_{\tilde{A}^{I}}\left(x_{2}\right)\right\}, \forall x_{1}, x_{2} \in X, \lambda \in[0,1]
$$

Definition 2. An IFN is shown as

$$
\prec x, \mu_{\tilde{A}^{I}}(x), v_{\tilde{A}^{I}}(x) \succ=\left(a^{1}, a^{2}, a^{3}, a^{4} ; b^{1}, b^{2}, b^{3}, b^{4}\right)
$$

such that degrees of membership $\mu_{\tilde{A}^{I}}(x)$ and non-membership $v_{\tilde{A}^{I}}(x)$ are as follows:

$$
\mu_{\tilde{A}^{I}}(x)=\left\{\begin{array}{l}
f(x), a^{1} \leq x<a^{2} \\
1, a^{2} \leq x \leq a^{3} \\
g(x), a^{3}<x \leq a^{4} \\
0 \text { otherwise }
\end{array} \quad \text { and } \quad v_{\tilde{A}^{I}}(x)=\left\{\begin{array}{l}
h(x), b^{1} \leq x<b^{2} \\
0, b^{2} \leq x \leq b^{3} \\
k(x), b^{3}<x \leq b^{4} \\
1 \text { otherwise }
\end{array}\right.\right.
$$

where $f, k$ are monotonically increasing functions and $g, h$ are monotonically decreasing functions. 


\subsubsection{Triangular intuitionistic fuzzy number}

Definition 3 [41]. An IFN is called a triangular intuitionistic fuzzy number (TIFN) if its membership function $\mu_{\tilde{A}^{I}}(x)$ and non-membership function $v_{\tilde{A}^{I}}(x)$ are as follows:

$$
\mu_{\tilde{A}^{I}}(x)=\left\{\begin{array}{l}
\frac{x-a^{1}}{a^{2}-a^{1}}, \quad a^{1} \leq x<a^{2} \\
1, x=a^{2} \\
\frac{x-a^{3}}{a^{2}-a^{3}}, a^{2}<x \leq a^{3} \\
0 \text { otherwise }
\end{array} \quad \text { and } \quad v_{\tilde{A}^{I}}(x)=\left\{\begin{array}{l}
\frac{x-a^{2}}{a^{1^{\prime}}-a^{2}}, \quad a^{1^{\prime}} \leq x<a^{2} \\
0, x=a^{2} \\
\frac{x-a^{2}}{a^{3^{\prime}}-a^{3}}, a^{2}<x \leq a^{3^{\prime}} \\
1 \text { otherwise }
\end{array}\right.\right.
$$

where $a^{1^{\prime}} \leq a^{1} \leq a^{2} \leq a^{3} \leq a^{3^{\prime}}$. This TIFN is represented by $\tilde{A}^{I}=\left(a^{1}, a^{2}, a^{3} ; a^{1^{\prime}}, a^{2}, a^{3^{\prime}}\right)$.

\subsubsection{Arithmetic operations on intuitionistic fuzzy numbers}

Consider two TIFNs like $\tilde{A}^{I}$ and $\tilde{B}^{I}$ as follows:

$$
\tilde{A}^{I}=\left(a^{1}, a^{2}, a^{3} ; a^{1^{\prime}}, a^{2}, a^{3^{\prime}}\right) \text { and } \tilde{B}^{I}=\left(b^{1}, b^{2}, b^{3} ; b^{1^{\prime}}, b^{2}, b^{3^{\prime}}\right)
$$

Then, the following relationships hold:

$$
\begin{aligned}
& \text { (i): } \tilde{A}^{I} \oplus \tilde{B}^{I}=\left(a^{1}+b^{1}, a^{2}+b^{2}, a^{3}+b^{3} ; a^{1^{\prime}}+b^{1^{\prime}}, a^{2}+b^{2}, a^{3^{\prime}}+b^{3^{\prime}}\right) \\
& \text { (ii): } \tilde{A}^{I} \otimes \tilde{B}^{I} \approx\left(a^{1} b^{1}, a^{2} b^{2}, a^{3} b^{3} ; a^{1^{\prime}} b^{1^{\prime}}, a^{2} b^{2}, a^{3^{\prime}} b^{3^{\prime}}\right) \\
& \text { (iii): for } k \in R k \tilde{A}^{I}=\left\{\begin{array}{l}
\left(k a^{1}, k a^{2}, k a^{3} ; k a^{1^{\prime}}, k a^{2}, k a^{3^{\prime}}\right), k>0 \\
\left(k a^{3}, k a^{2}, k a^{1} ; k a^{3^{\prime}}, k a^{2}, k a^{1^{\prime}}\right), k<0
\end{array}\right.
\end{aligned}
$$

\subsubsection{Expected values of intuitionistic fuzzy numbers and their characteristics}

Definition 4 [22]. If $\tilde{A}^{I}=\left(a^{1}, a^{2}, a^{3}, a^{4} ; b^{1}, b^{2}, b^{3}, b^{4}\right)$ is an IFN, then the expected interval of this number is defined as follows: 


$$
E I\left(\tilde{A}^{I}\right)=\left[E_{L}\left(\tilde{A}^{I}\right), E_{R}\left(\tilde{A}^{I}\right)\right]
$$

where

$$
E_{L}\left(\tilde{A}^{I}\right)=\frac{b^{1}+a^{2}}{2}+\frac{1}{2} \int_{b^{1}}^{b^{2}} h(x)-\frac{1}{2} \int_{a^{1}}^{a^{2}} f(x) d x
$$

and

$$
E_{R}\left(\tilde{A}^{I}\right)=\frac{a^{3}+b^{4}}{2}+\frac{1}{2} \int_{a^{3}}^{a^{4}} g(x)-\frac{1}{2} \int_{b^{3}}^{b^{4}} k(x) d x
$$

Accordingly, the expected value based on this IFN, is defined as

$$
E V\left(\tilde{A}^{I}\right)=\frac{\left(E_{L}\left(\tilde{A}^{I}\right)+E_{R}\left(\tilde{A}^{I}\right)\right)}{2}
$$

Proposition 1. If $\tilde{A}^{I}=\left(a^{1}, a^{2}, a^{3} ; a^{1^{\prime}}, a^{2}, a^{3^{\prime}}\right)$ is a TIFN, then $E I\left(\tilde{A}^{I}\right)$ is equal to

$$
E I\left(\tilde{A}^{I}\right)=\left[\frac{a^{1^{\prime}}+2 a^{2}+a^{1}}{4}, \frac{a^{3}+2 a^{2}+a^{3^{\prime}}}{4}\right]
$$

So, the expected value for a TIFN is equal to

$$
E V\left(\tilde{A}^{I}\right)=\frac{a^{1^{\prime}}+a^{1}+4 a^{2}+a^{3}+a^{3^{\prime}}}{8}
$$

Proposition 2. The expected value is a linear relationship, in the sense that the following relationship holds for any two intuitionistic fuzzy numbers like $\tilde{A}^{I}$ and $\tilde{B}^{I}$ :

$$
E V\left(\tilde{A}^{I}+\tilde{B}^{I}\right)=E V\left(\tilde{A}^{I}\right)+E V\left(\tilde{B}^{I}\right)
$$

\subsection{Two-stage data envelopment analysis}

DEA was first introduced by Charnes et al. [8] who developed a model called CCR for evaluating a set of $D M U$ s. The traditional DEA models evaluate the relative efficiency of $D M U$ s using a "black box" approach which means focusing on the weights of 
inputs and outputs and ignoring the internal processes of the evaluated units. Some DEA models, like network-type models, take a different approach to efficiency evaluation. In the network DEA, various stages of production are linked to each other through intermediate products which are the outputs of one stage and the inputs of another stage. The two-stage structure was first introduced by Fare [20] and then expanded by other researchers $[18,19]$. Initially, these structures were designed such that only the outputs of the first stage could be the input of the second stage [19]. But later, the two-stage network models were expanded to allow the second stage to receive other inputs as well as the outputs of the first stage. Efficiency evaluation in two-stage systems is a major subfield of DEA.

The most famous two-stage approaches are Kao and Hwang [25] and Chen et al. [9]. One of the limitations of the model of Kao and Hwang [18] is its inability to handle under the VRS assumption. As their model remains linear under the CRS assumption, but under the VRS assumption, it is converted into a non-linear form. Therefore, Chen et al. [9] introduced an additive model in 2009, which is obtained from the model of Kao and Hwang [25], and then they have combined the efficiency of the stages and calculated the overall efficiency by using the weighted additive approach. The multiplicative method in the model of Kao and Hwang [25] and the developed model of Kao and Hwang [25] by Chen et al. [9] have a decomposition approach which is the first estimate the overall efficiency and then the efficiency of each stage is calculated based on the obtained optimal solution of the overall efficiency. However, Despotis et al. [16] showed that the proposed approach by Chen et al. [9] have two shortcomings.

The first shortcoming given in Chen et al. [9] that discussed by Despotis et al. [16] for the weights $W_{1}$ and $W_{2}$, they represent the relative contribution of two-stage to the overall performance of the $D M U$ in the two-stage DEA model, but as long as the weights derive from the optimal solution, they depend on the $D M U$ being evaluated and they are different for different $D M U$ s. Hence, the size of a stage is not an objective reality, as it is viewed differently from each $D M U$ in the two-stage DEA model. The second shortcoming to Chen et al. [9], is much more important. According to the definition of weights and the optimal value in the weighted additive method of this approach, the second weight is always less than or equal to the first weight. This bias of the weights is a big shortcoming as it biases the stage efficiencies. Also, the bias of the stages leads to the bias of the overall efficiency. To overcome these shortcomings, Despotis et al. [16] presented a bias-free approach to assess unique efficiency score for two stages, which are then aggregated to get the overall efficiency score of evaluated units, without any necessary to define the overall efficiency at first. For this reason, this method has been named the composition approach. Therefore, in this paper, the proposed model by Despotis et al. [16] is used. 


\section{Development of the two-stage DEA model in the intuitionistic fuzzy environment using a combined approach}

The approach proposed by Despotis et al. [16] for efficiency evaluation of two-stage systems in an intuitionistic fuzzy environment is to make unique evaluations of the two stages simultaneously. In this approach, to determine the efficiency of a two-stage $D M U$, the first stage is treated as an output-oriented subunit and the second stage is treated as an input-oriented subunit, with the same intermediate weights used for both stages. Then, the two subunits are adjusted in terms of the values of efficiency to maximise the overall efficiency. In the following, we first present a brief description of the model of Despotis et al. [16], Consider the problem of evaluating the efficiency of $n$ two-stage decision-making units $D M U_{j}, j=1, \ldots, n$, each using $m$ inputs $X_{i j}, i=1, \ldots, m$, in the first stage to produce $D$ outputs or intermediate measures $Z_{d j}, d=1, \ldots, D$, which are then used as the inputs of the second stage. The output of the second stage is denoted by $Y_{r j}, r=1, \ldots, s$. For this problem, the overall efficiency of the two-stage system based on the model of Despotis et al. [16] will be as follows:

Remark 1. The overall efficiency is obtained by aggregative the two objective functions additively, $E_{1}=\sum_{i=1}^{m} v_{i} x_{i j_{o}}$, which is the efficiency of the first stage based on a minimisation model, and $E_{2}=\sum_{r=1}^{s} u_{r} y_{r j_{0}}$, which is the efficiency of the second stage based on a maximisation model. This method can evaluate the efficiency score of the two stages together with a common weight simultaneously, as two stages tend to work together to maximise the overall efficiency score of the $D M U_{j_{\circ}}$. Then single-objective program is as follows:

$$
\begin{aligned}
& \min \sum_{i=1}^{m} v_{i} x_{i j_{\circ}}-\sum_{r=1}^{s} u_{r} y_{r j_{\circ}} \\
& \text { s.t. } \\
& \sum_{d=1}^{f} w_{d} z_{d j_{\circ}}=1, \quad j=1, \ldots, n \\
& \sum_{d=1}^{f} w_{d} z_{d j}-\sum_{i=1}^{m} v_{i} x_{i j} \leq 0, \quad j=1, \ldots, n \\
& \sum_{r=1}^{s} u_{r} y_{r j}-\sum_{d=1}^{f} w_{d} z_{d j} \leq 0, \quad j=1, \ldots, n \\
& v_{i}, w_{d}, u_{r} \geq 0, \quad i=1, \ldots, m ; d=1, \ldots, f ; r=1, \ldots, s
\end{aligned}
$$


Remark 2. If $\left(v_{i}^{*}, u_{r}^{*}\right)$ is an optimal solution of model (9), the efficiency score for unit $j_{\circ}$ in the first and the second stages will be, respectively, $E_{1}^{*}=\frac{1}{\sum_{i=1}^{m} v_{i}^{*} x_{i j_{0}}}$ and $E_{2}^{*}=\sum_{r-1}^{s} u_{r}^{*} y_{r j}$, because the purpose is to minimise the objective function of model (9). Hence, according to the multiplicative method introduced by Kao and Hwang [25], the overall efficiency and the stage efficiencies of the $D M U_{j_{0}}$ are defined as: $E^{*}=E_{1}^{*} \times E_{2}^{*}$. The ptimal value of the objective function of model (9) is: $\sum_{i=1}^{m} v_{i}^{*} x_{i j_{o}}-\sum_{r=1}^{s} u_{r}^{*} y_{r j_{o}} \geq 0$.

The unit $j_{\circ}$ is efficient in both stages and thus, overall efficient, if and only if the optimal value of the objective function is zero. Otherwise, it is overall inefficient. However, it is the normalisation constraint $\sum_{d=1}^{f} w_{d} z_{d j_{0}}=1$, on the intermediate measures in model (9) that allows us to infer the efficiency scores of the individual stages, as given respectively $E_{1}^{*}=\sum_{i=1}^{m} v_{i}^{*} x_{i j_{0}}$ and $E_{2}^{*}=\sum_{r=1}^{s} \frac{1}{u_{r}^{*} y_{r j_{0}}}$.

If the variables are intuitionistic fuzzy numbers, then model (9) can be rewritten into model (10).

$$
\begin{aligned}
& \min \sum_{i=1}^{m} \tilde{v}_{i}^{I} \otimes \tilde{x}_{i j_{0}}^{I} \Theta \sum_{r=1}^{s} \tilde{u}_{r}^{I} \otimes \tilde{y}_{r j_{\circ}}^{I} \\
& \text { s.t. } \\
& \sum_{d=1}^{f} \tilde{w}_{d}^{I} \otimes \tilde{z}_{d j o}^{I}=1, \quad j=1, \ldots, n \\
& \sum_{d=1}^{f} \tilde{w}_{d}^{I} \otimes \tilde{z}_{d j}^{I} \Theta \sum_{i=1}^{m} \tilde{v}_{i}^{I} \otimes \tilde{x}_{i j}^{I} \leq 0, \quad j=1, \ldots, n \\
& \sum_{r=1}^{s} \tilde{u}_{r}^{I} \otimes \tilde{y}_{r j}^{I} \Theta \sum_{d=1}^{f} \tilde{w}_{d}^{I} \otimes \tilde{z}_{d j}^{I} \leq 0, \quad j=1, \ldots, n \\
& \tilde{v}_{i}^{I}, \tilde{w}_{d}^{I}, \tilde{u}_{r}^{I}>0, \quad i=1, \ldots, m ; d=1, \ldots, f ; r=1, \ldots, s
\end{aligned}
$$

The present study aims to expand this two-stage DEA model based on intuitionistic triangular fuzzy numbers. Therefore, model (10) is rewritten based on triangular intuitionistic fuzzy numbers and the method of Puri and Yadav [43]: 


$$
\begin{aligned}
& \sum_{i=1}^{m}\left(v_{i}^{1}, v_{i}^{2}, v_{i}^{3} ; v_{i}^{1^{\prime}}, v_{i}^{2}, v_{i}^{3^{\prime}}\right) \otimes\left(x_{i j_{\circ}}^{1}, x_{i j_{\circ}}^{2}, x_{i j_{0}}^{3} ; x_{i j_{\circ}}^{1^{\prime}}, x_{i j_{\circ}}^{2}, x_{i j_{0}}^{3^{\prime}}\right) \Theta \\
& \sum_{r=1}^{s}\left(u_{r}^{1}, u_{r}^{2}, u_{r}^{3} ; u_{r}^{1^{\prime}}, u_{r}^{2}, u_{r}^{3^{\prime}}\right) \otimes\left(y_{r j_{\circ}}^{1}, y_{r j_{\circ}}^{2}, y_{r j_{\circ}}^{3} ; y_{r j_{\circ}}^{1^{\prime}}, y_{r j_{\circ}}^{2}, y_{r j_{\circ}}^{3^{\prime}}\right)
\end{aligned}
$$

s.t.

$$
\begin{aligned}
& \sum_{d=1}^{f}\left(w_{d}^{1}, w_{d}^{2}, w_{d}^{3} ; w_{d}^{1^{\prime}}, w_{d}^{2}, w_{d}^{3^{\prime}}\right) \otimes\left(z_{d j_{0}}^{1}, z_{d j_{0}}^{2}, z_{d j}^{3} ; z_{d j_{0}}^{1^{\prime}}, z_{d j_{0}}^{2}, z_{d j_{0}}^{3^{\prime}}\right) \\
& \quad=(1,1,1 ; 1,1,1), \quad j=1, \ldots, n \\
& \sum_{d=1}^{f}\left(w_{d}^{1}, w_{d}^{2}, w_{d}^{3} ; w_{d}^{1^{\prime}}, w_{d}^{2}, w_{d}^{3^{\prime}}\right) \otimes\left(z_{d j}^{1}, z_{d j}^{2}, z_{d j}^{3} ; z_{d j}^{1^{\prime}}, z_{d j}^{2}, z_{d j}^{3^{\prime}}\right) \Theta \\
& \sum_{i=1}^{m}\left(v_{i}^{1}, v_{i}^{2}, v_{i}^{3} ; v_{i}^{1^{\prime}}, v_{i}^{2}, v_{i}^{3^{\prime}}\right) \otimes\left(x_{i j}^{1}, x_{i j}^{2}, x_{i j}^{3} ; x_{i j}^{1^{\prime}}, x_{i j}^{2}, x_{i j}^{3^{\prime}}\right) \\
& \quad \leq(0,0,0 ; 0,0,0), \quad j=1, \ldots, n \\
& \sum_{r=1}^{s}\left(u_{r}^{1}, u_{r}^{2}, u_{r}^{3} ; u_{r}^{1^{\prime}}, u_{r}^{2}, u_{r}^{3^{\prime}}\right) \otimes\left(y_{r j}^{1}, y_{r j}^{2}, y_{r j}^{3} ; y_{r j}^{1^{\prime}}, y_{r j}^{2}, y_{r j}^{3^{\prime}}\right) \Theta \\
& \sum_{d=1}^{f}\left(w_{d}^{1}, w_{d}^{2}, w_{d}^{3} ; w_{d}^{1^{\prime}}, w_{d}^{2}, w_{d}^{3^{\prime}}\right) \otimes\left(z_{d j}^{1}, z_{d j}^{2}, z_{d j}^{3} ; z_{d j}^{1^{\prime}}, z_{d j}^{2}, z_{d j}^{3^{\prime}}\right) \\
& \leq(0,0,0 ; 0,0,0), \quad j=1, \ldots, n \\
& \left(v_{i}^{1}, v_{i}^{2}, v_{i}^{3} ; v_{i}^{1^{\prime}}, v_{i}^{2}, v_{i}^{3^{\prime}}\right)>0, \quad i=1, \ldots, m \\
& \left(w_{d}^{1}, w_{d}^{2}, w_{d}^{3} ; w_{d}^{1^{\prime}}, w_{d}^{2}, w_{d}^{3^{\prime}}\right)>0, \quad d=1, \ldots, f \\
& \left(u_{r}^{1}, u_{r}^{2}, u_{r}^{3} ; u_{r}^{1^{\prime}}, u_{r}^{2}, u_{r}^{3^{\prime}}\right)>0, \quad r=1, \ldots, s
\end{aligned}
$$

As based on the intuitionistic triangular fuzzy numbers operators in Equation (3), model (11) can be rewritten into model (12).

$$
\min \left(\begin{array}{l}
\sum_{i=1}^{m} v_{i}^{1} x_{i j_{\circ}}^{1}-\sum_{r=1}^{s} u_{r}^{3} y_{r j_{\circ}}^{3}, \sum_{i=1}^{m} v_{i}^{2} x_{i j_{\circ}}^{2}-\sum_{r=1}^{s} u_{r}^{2} y_{r j_{\circ}}^{2}, \sum_{i=1}^{m} v_{i}^{3} x_{i j_{\circ}}^{3}-\sum_{r=1}^{s} u_{r}^{1} y_{r j_{\circ}}^{1} \\
\sum_{i=1}^{m} v_{i}^{1^{\prime}} x_{i j_{\circ}}^{1^{\prime}}-\sum_{r=1}^{s} u_{r}^{3^{\prime}} y_{r j_{\circ}}^{3^{\prime}}, \sum_{i=1}^{m} v_{i}^{2} x_{i j_{\circ}}^{2}-\sum_{r=1}^{s} u_{r}^{2} y_{r j_{\circ}}^{2}, \sum_{i=1}^{m} v_{i}^{3^{\prime}} x_{i j_{\circ}}^{3^{\prime}}-\sum_{r=1}^{s} u_{r}^{1^{\prime}} y_{r j_{\circ}}^{1^{\prime}}
\end{array}\right)
$$

$$
\begin{gathered}
\sum_{d=1}^{f} w_{d}^{1} z_{d j_{0}}^{1}, \sum_{d=1}^{f} w_{d}^{2} z_{d j_{0}}^{2}, \sum_{d=1}^{f} w_{d}^{3} z_{d j_{0}}^{3} ; \sum_{d=1}^{f} w_{d}^{1^{\prime}} z_{d j_{0}}^{1^{\prime}}, \sum_{d=1}^{f} w_{d}^{2} z_{d j_{0}}^{2}, \sum_{d=1}^{f} w_{d}^{3^{\prime}} z_{d j_{\circ}}^{3^{\prime}} \\
=(1,1,1 ; 1,1,1) \quad j=1, \ldots, n
\end{gathered}
$$




$$
\begin{aligned}
& \left(\begin{array}{l}
\sum_{d=1}^{f} w_{d}^{1} z_{d j}^{1}-\sum_{i=1}^{m} v_{i}^{3} x_{i j}^{3}, \sum_{d=1}^{f} w_{d}^{2} z_{d j}^{2}-\sum_{i=1}^{m} v_{i}^{2} x_{i j}^{2}, \sum_{d=1}^{f} w_{d}^{3} z_{d j}^{3}-\sum_{i=1}^{m} v_{i}^{1} x_{i j}^{1} ; \\
\sum_{d=1}^{f} w_{d}^{1^{\prime}} z_{d j}^{1^{\prime}}-\sum_{i=1}^{m} v_{i}^{3^{\prime}} x_{i j}^{3^{\prime}}, \sum_{d=1}^{f} w_{d}^{2} z_{d j}^{2}-\sum_{i=1}^{m} v_{i}^{2} x_{i j}^{2}, \sum_{d=1}^{f} w_{d}^{3^{\prime}} z_{d j}^{3^{\prime}}-\sum_{i=1}^{m} v_{i}^{1^{\prime}} x_{i j}^{1^{\prime}}
\end{array}\right) \\
& \leq(0,0,0 ; 0,0,0), \quad j=1, . ., n \\
& \left(\begin{array}{l}
\sum_{r=1}^{s} u_{r}^{1} y_{r j}^{1}-\sum_{d=1}^{f} w_{d}^{3} z_{d j}^{3}, \sum_{r=1}^{s} u_{r}^{2} y_{r j o}^{2}-\sum_{d=1}^{f} w_{d}^{2} z_{d j}^{2}, \sum_{r=1}^{s} u_{r}^{3} y_{r j}^{3}-\sum_{d=1}^{f} w_{d}^{1} z_{d j}^{1} \\
\sum_{r=1}^{s} u_{r}^{1^{\prime}} y_{r j}^{1^{\prime}}-\sum_{d=1}^{f} w_{d}^{3^{\prime}} z_{d j}^{3^{\prime}}, \sum_{r=1}^{s} u_{r}^{2} y_{r j}^{2}-\sum_{d=1}^{f} w_{d}^{2} z_{d j}^{2}, \sum_{r=1}^{s} u_{r}^{3^{\prime}} y_{r j}^{3^{\prime}}-\sum_{d=1}^{f} w_{d}^{1^{\prime}} z_{d j}^{1^{\prime}}
\end{array}\right) \\
& \leq(0,0,0 ; 0,0,0), \quad j=1, \ldots, n \\
& \left(v_{i}^{1}, v_{i}^{2}, v_{i}^{3} ; v_{i}^{1^{\prime}}, v_{i}^{2}, v_{i}^{3^{\prime}}\right)>0, \quad i=1, . ., m \\
& \left.w_{d}^{1}, w_{d}^{2}, w_{d}^{3} ; w_{d}^{1^{\prime}}, w_{d}^{2}, w_{d}^{3^{\prime}}\right)>0, \quad d=1, \ldots, f \\
& \left(u_{r}^{1}, u_{r}^{2}, u_{r}^{3} ; u_{r}^{1^{\prime}}, u_{r}^{2}, u_{r}^{3^{\prime}}\right)>0, \quad r=1, \ldots, s
\end{aligned}
$$

As can be seen, this model is represented by intuitionistic fuzzy numbers (6 components). Therefore, the expected values of intuitionistic fuzzy numbers are used to convert this model into a linear crisp model. By obtaining the expected value of the objective function and constraints of model (12), this model can be turned into model (13).

$\min E V\left(\left(\begin{array}{l}\sum_{i=1}^{m} v_{i}^{1} x_{i j_{\circ}}^{1}-\sum_{r=1}^{s} u_{r}^{3} y_{r j_{\circ}}^{3}, \sum_{i=1}^{m} v_{i}^{2} x_{i j_{\circ}}^{2}-\sum_{r=1}^{s} u_{r}^{2} y_{r j_{\circ}}^{2}, \sum_{i=1}^{m} v_{i}^{3} x_{i j_{\circ}}^{3}-\sum_{r=1}^{s} u_{r}^{1} y_{r j_{\circ}}{ }^{1} ; \\ \sum_{i=1}^{m} v_{i}^{1^{\prime}} x_{i j_{\circ}}^{1^{\prime}}-\sum_{r=1}^{s} u_{r}^{3^{\prime}} y_{r j_{\circ}}^{3^{\prime}}, \sum_{i=1}^{m} v_{i}^{2} x_{i j_{\circ}}^{2}-\sum_{r=1}^{s} u_{r}^{2} y_{r j_{\circ}}^{2}, \sum_{i=1}^{m} v_{i}^{3^{\prime}} x_{i j_{\circ}}^{3^{\prime}}-\sum_{r=1}^{s} u_{r}^{1^{\prime}} y_{r j_{\circ}}^{1^{\prime}}\end{array}\right)\right)$

s.t.

$$
\begin{aligned}
& E V\left(\sum_{d=1}^{f} w_{d}^{1} z_{d j_{0}}^{1}, \sum_{d=1}^{f} w_{d}^{2} z_{d j_{0}}^{2}, \sum_{d=1}^{f} w_{d}^{3} z_{d j_{0}}^{3} ; \sum_{d=1}^{f} w_{d}^{1^{\prime}} z_{d j_{0}}^{1^{\prime}}, \sum_{d=1}^{f} w_{d}^{2} z_{d j_{0}}^{2}, \sum_{d=1}^{f} w_{d}^{3^{\prime}} z_{d j_{0}}^{3^{\prime}}\right) \\
& =E V((1,1,1 ; 1,1,1)), j=1, . ., n \\
& E V\left(\left(\begin{array}{l}
\left.\left.\sum_{d=1}^{f} w_{d}^{1} z_{d j}^{1}-\sum_{i=1}^{m} v_{i}^{3} x_{i j}^{3}, \sum_{d=1}^{f} w_{d}^{2} z_{d j}^{2}-\sum_{i=1}^{m} v_{i}^{2} x_{i j}^{2}, \sum_{d=1}^{f} w_{d}^{3} z_{d j}^{3}-\sum_{i=1}^{m} v_{i}^{1} x_{i j}^{1} ;\right)\right) \\
\sum_{d=1}^{f} w_{d}^{1^{\prime}} z_{d j}^{1^{\prime}}-\sum_{i=1}^{m} v_{i}^{3^{\prime}} x_{i j}^{3^{\prime}}, \sum_{d=1}^{f} w_{d}^{2} z_{d j}^{2}-\sum_{i=1}^{m} v_{i}^{2} x_{i j}^{2}, \sum_{d=1}^{f} w_{d}^{3^{\prime}} z_{d j}^{3^{\prime}}-\sum_{i=1}^{m} v_{i}^{1^{\prime}} x_{i j}^{1^{\prime}},
\end{array}\right)\right) \\
& \leq E V((0,0,0 ; 0,0,0)), \quad j=1, \ldots, n
\end{aligned}
$$




$$
\begin{aligned}
E V & \left.\left(\begin{array}{l}
\left.\left(\sum_{r=1}^{s} u_{r}^{1} y_{r j}^{1}-\sum_{d=1}^{f} w_{d}^{3} z_{d j}^{3}, \sum_{r=1}^{s} u_{r}^{2} y_{r j o}^{2}-\sum_{d=1}^{f} w_{d}^{2} z_{d j}^{2}, \sum_{r=1}^{s} u_{r}^{3} y_{r j}^{3}-\sum_{d=1}^{f} w_{d}^{1} z_{d j}^{1} ;\right)\right) \\
\left.\sum_{r=1}^{s} u_{r}^{1^{\prime}} y_{r j}^{1^{\prime}}-\sum_{d=1}^{f} w_{d}^{3^{\prime}} z_{d j}^{3^{\prime}}, \sum_{r=1}^{s} u_{r}^{2} y_{r j}^{2}-\sum_{d=1}^{f} w_{d}^{2} z_{d j}^{2}, \sum_{r=1}^{s} u_{r}^{3^{\prime}} y_{r j}^{3^{\prime}}-\sum_{d=1}^{f} w_{d}^{1^{\prime}} z_{d j}^{1^{\prime}}\right)
\end{array}\right)\right) \\
& \leq E V((0,0,0 ; 0,0,0)), \quad j=1, \ldots, n \\
v_{i}^{3^{\prime}} \geq & v_{i}^{3} \geq v_{i}^{2} \geq v_{i}^{1} \geq v_{i}^{1^{\prime}}>0, \quad i=1, \ldots, m \\
w_{d}^{3^{\prime}} \geq & w_{d}^{3} \geq w_{d}^{2} \geq w_{d}^{1} \geq w_{d}^{1^{\prime}}>0, \quad d=1, \ldots, f \\
u_{r}^{3^{\prime}} \geq & u_{r}^{3} \geq u_{r}^{2} \geq u_{r}^{1} \geq u_{r}^{1^{\prime}}>0, \quad r=1, \ldots, s
\end{aligned}
$$

Then, equation (7) is used to calculate the expected value of the intuitionistic triangular fuzzy numbers and rewrite the second proposition of model (13) into the linear promising model (14).

$$
\min \frac{1}{8}\left(\begin{array}{c}
\sum_{i=1}^{m}\left(v_{i}^{1^{\prime}} x_{i j_{\circ}}^{1^{\prime}}+v_{i}^{1} x_{i j_{\circ}}^{1}+4 v_{i}^{2} x_{i j_{o}}^{2}+v_{i}^{3} x_{i j_{\circ}}^{3}+v_{i}^{3^{\prime}} x_{i j_{\circ}}^{3^{\prime}}\right)- \\
\sum_{r=1}^{s}\left(u_{r}^{1^{\prime}} y_{r j_{\circ}}^{1^{\prime}}+u_{r}^{1} y_{r j_{\circ}}^{1}+4 u_{r}^{2} y_{r j_{\circ}}^{2}+u_{r}^{3} y_{r j_{\circ}}^{3}+u_{r}^{3^{\prime}} y_{r j_{\circ}}^{3^{\prime}}\right)
\end{array}\right)
$$

s.t.

$$
\begin{aligned}
& \sum_{d=1}^{f}\left(w_{d}^{1^{\prime}} z_{d j_{0}}^{1^{\prime}}+w_{d}^{1} z_{d j_{0}}^{1}+4 w_{d}^{2} z_{d j_{0}}^{2}+w_{d}^{3} z_{d j_{0}}^{3}+w_{d}^{3^{\prime}} z_{d j_{\circ}}^{3^{\prime}}\right)=8, \quad j=1, \ldots, n \\
& \frac{1}{8}\left(\begin{array}{l}
\sum_{d=1}^{f}\left(w_{d}^{1^{\prime}} z_{d j}^{1^{\prime}}+w_{d}^{1} z_{d j}^{1}+4 w_{d}^{2} z_{d j}^{2}+w_{d}^{3} z_{d j}^{3}+w_{d}^{3^{\prime}} z_{d j}^{3^{\prime}}\right)- \\
\sum_{i=1}^{m}\left(v_{i}^{1^{\prime}} x_{i j}^{1^{\prime}}+v_{i}^{1} x_{i j}^{1}+4 v_{i}^{2} x_{i j}^{2}+v_{i}^{3} x_{i j}^{3}+v_{i}^{3^{\prime}} x_{i j}^{3^{\prime}}\right)
\end{array}\right) \leq 0, \quad j=1, \ldots, n \\
& \frac{1}{8}\left(\begin{array}{l}
\sum_{r=1}^{s}\left(u_{r}^{1^{\prime}} y_{r j}^{1^{\prime}}+u_{r}^{1} y_{r j}^{1}+4 u_{r}^{2} y_{r j}^{2}+u_{r}^{3} y_{r j}^{3}+u_{r}^{3^{\prime}} y_{r j}^{3^{\prime}}\right)- \\
\sum_{d=1}^{f}\left(w_{d}^{1^{\prime}} z_{d j}^{1^{\prime}}+w_{d}^{1} z_{d j}^{1}+4 w_{d}^{2} z_{d j}^{2}+w_{d}^{3} z_{d j}^{3}+w_{d}^{3^{\prime}} z_{d j}^{3^{\prime}}\right)
\end{array}\right) \leq 0, \quad j=1, \ldots, n \\
& v_{i}^{3^{\prime}} \geq v_{i}^{3} \geq v_{i}^{2} \geq v_{i}^{1} \geq v_{i}^{1^{\prime}}>0, \quad i=1, \ldots, m \\
& w_{d}^{3^{\prime}} \geq w_{d}^{3} \geq w_{d}^{2} \geq w_{d}^{1} \geq w_{d}^{1^{\prime}}>0, \quad d=1, \ldots, f \\
& u_{r}^{3^{\prime}} \geq u_{r}^{3} \geq u_{r}^{2} \geq u_{r}^{1} \geq u_{r}^{1^{\prime}}>0, \quad r=1, \ldots, s
\end{aligned}
$$

Solving model (14) gives the overall efficiency of each $D M U$, i.e., the $E^{*}$ discussed in Remark 2, based on intuitionistic triangular fuzzy numbers. 


\section{Numerical example}

The computational process of the introduced model will be illustrated by running the model on intuitionistic fuzzy data sets. The problem used for this purpose has $12 \mathrm{DMUs}$, each having 3 inputs in the first stage, 2 intermediate products, and 3 outputs in the second stage. The general model of these $D M U$ s is shown in Fig. 1. The triangular intuitionistic fuzzy data of the above example are presented in Tables 1-3.

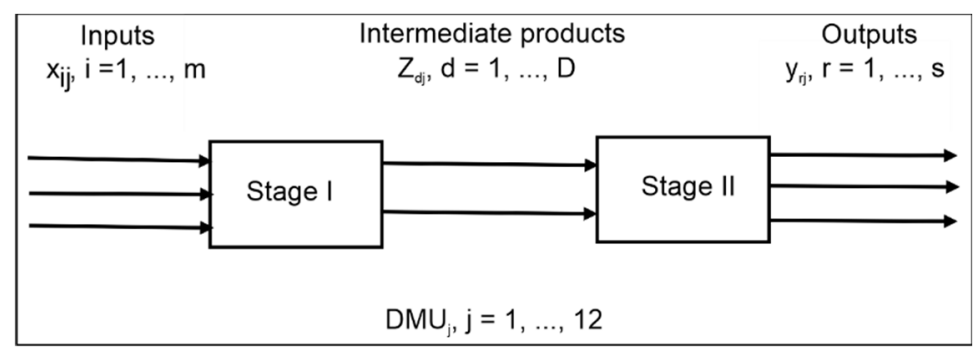

Fig. 1. Two-stage model of the numerical example

Table 1. Triangular intuitionistic fuzzy inputs in stage I assumed for $12 \mathrm{DMUs}$

\begin{tabular}{|c|c|c|c|}
\hline DMU & Input 1 & Input 2 & Input 3 \\
\hline \multirow{2}{*}{1} & $(6,6.5,7 ;$ & $(4.87,5.37,5.87 ;$ & $(5.6,6.1,6.6 ;$ \\
& $5.5,6.5,8)$ & $4.37,5.37,6.87)$ & $5.1,6.1,7.6)$ \\
\hline \multirow{2}{*}{2} & $(5.33,5.83,6.33 ;$ & $(4.88,5.38,5.88 ;$ & $(3.94,4.44,4.94 ;$ \\
& $4.83,5.83,7.33)$ & $4.38,5.38,6.88)$ & $3.44,4.44,5.94)$ \\
\hline \multirow{2}{*}{3} & $\begin{array}{c}(5.31,5.81,6.31 ; \\
\end{array}$ & $(4.79,5.29,5.79 ;$ & $(5.37,5.87,6.37 ;$ \\
\hline \multirow{2}{*}{4} & $(5.5,6,6.5 ;$ & $(4.81,5.31,5.81 ;$ & $(5.38,5.88,6.38 ;$ \\
& $5,6,7.5)$ & $4.31,5.31,6.81)$ & $4.88,5.88,7.38)$ \\
\hline \multirow{2}{*}{5} & $(4.65,5.15,5.65 ;$ & $(4.23,4.73,5.23 ;$ & $(4.45,4.95,5.45 ;$ \\
& $4.15,5.15,6.65)$ & $3.73,4.73,6.23)$ & $3.95,4.95,6.45)$ \\
\hline \multirow{2}{*}{6} & $(4.45,4.95,5.45 ;$ & $(4.51,5.01,5.51 ;$ & $(4.36,4.86,5.36 ;$ \\
& $3.95,4.95,6.45)$ & $4.01,5.01,6.51)$ & $3.86,4.86,6.36)$ \\
\hline \multirow{2}{*}{7} & $(4.35,4.85,5.35 ;$ & $(3.71,4.21,4.71 ;$ & $(4.78,5.28,5.78 ;$ \\
& $3.85,4.85,6.35)$ & $3.21,4.21,5.71)$ & $4.28,5.28,6.78)$ \\
\hline \multirow{2}{*}{8} & $(4.92,5.42,5.92 ;$ & $(4.14,4.64,5.14 ;$ & $(4.64,5.14,5.64 ;$ \\
& $4.42,5.42,6.92)$ & $3.64,4.64,6.14)$ & $4.14,5.14,6.64)$ \\
\hline \multirow{2}{*}{9} & $(4.85,5.35,5.85 ;$ & $(4.14,4.64,5.14 ;$ & $(4.64,5.14,5.64 ;$ \\
& $4.35,5.35,6.85)$ & $3.64,4.64,6.14)$ & $4.14,5.14,6.64)$ \\
\hline \multirow{2}{*}{10} & $(4.6,5.1,5.6 ;$ & $(4.05,4.55,5.05 ;$ & $(4.63,5.13,5.63 ;$ \\
& $4.1,5.1,6.6)$ & $3.55,4.55,6.05)$ & $4.13,5.13,6.63)$ \\
\hline \multirow{2}{*}{11} & $(3.48,3.98,4.48 ;$ & $(3.38,3.88,4.38 ;$ & $(3.71,4.21,4.71 ;$ \\
& $2.98,3.98,5.48)$ & $2.88,3.88,5.38)$ & $3.21,4.21,5.71)$ \\
\hline \multirow{2}{*}{12} & $(5.31,5.81,6.31 ;$ & $(4.41,4.91,5.41 ;$ & $(5.43,5.93,6.43 ;$ \\
& $4.81,5.81,7.31)$ & $3.91,4.91,6.41)$ & $4.93,5.93,7.43)$ \\
\hline \multirow{2}{*}{2} & & & \\
\hline
\end{tabular}


Table 2. Triangular intuitionistic fuzzy intermediate products assumed for $12 \mathrm{DMUs}$

\begin{tabular}{|c|c|c|c|c|c|}
\hline & Intermediate 1 & Intermediate 2 & $D M U$ & Intermediate 1 & Intermediate 2 \\
\hline 1 & $\begin{array}{l}(2.65,3.05,3.45 \\
2.35,3.05,4.15)\end{array}$ & $\begin{array}{l}(5.2,5.7,6.2 \\
4.7,5.7,7.2) \\
\end{array}$ & 7 & $\begin{array}{l}(2.57,2.97,3.37 \\
2.27,2.97,4.07)\end{array}$ & $\begin{array}{l}(4.36,4.86,5.36 ; \\
3.86,4.86,6.36)\end{array}$ \\
\hline 2 & $\begin{array}{l}(2.66,3.06,3.46 ; \\
2.36,3.06,4.16)\end{array}$ & $\begin{array}{l}(4.68,5.18,5.68 ; \\
4.18,5.18,6.68)\end{array}$ & 8 & $\begin{array}{l}(2.92,3.32,3.72 ; \\
2.62,3.32,4.42)\end{array}$ & $\begin{array}{l}(4.78,5.28,5.78 ; \\
4.28,5.28,6.78)\end{array}$ \\
\hline 3 & $\begin{array}{r}(4,4.4,4.8 \\
3.7,4.4,5.5) \\
\end{array}$ & $\begin{array}{l}(4.68,5.18,5.68 \\
4.18,5.18,6.68)\end{array}$ & 9 & $\begin{array}{l}(2.92,3.32,3.72 ; \\
2.62,3.32,4.42)\end{array}$ & $\begin{array}{l}(5.14,5.64,6.14 ; \\
4.64,5.64,7.14)\end{array}$ \\
\hline 4 & $\begin{array}{l}(4.44,4.84,5.24 \\
4.14,4.84,5.94)\end{array}$ & $\begin{array}{l}(6.05,6.55,7.05 \\
5.55,6.55,8.05)\end{array}$ & 10 & $\begin{array}{l}(2.66,3.06,3.46 \\
2.36,3.06,4.16)\end{array}$ & $\begin{array}{l}(3.96,4.46,4.96 ; \\
3.46,4.46,5.96)\end{array}$ \\
\hline 5 & $\begin{array}{l}(2.05,2.45,2.85 \\
1.75,2.45,3.55)\end{array}$ & $\begin{array}{l}(4.6,5.1,5.6 \\
4.1,5.1,6.6)\end{array}$ & 11 & $\begin{array}{l}(1.42,1.82,2.22 ; \\
1.12,1.82,2.92)\end{array}$ & $\begin{array}{l}(3.57,4.07,4.57 ; \\
3.07,4.07,5.57)\end{array}$ \\
\hline 6 & $\begin{array}{l}(2.68,3.08,3.48 ; \\
2.38,3.08,4.18)\end{array}$ & $\begin{array}{l}(4.3,4.8,5.3 \\
3.8,4.8,6.3) \\
\end{array}$ & 12 & $\begin{array}{r}(2,2.4,2.8 \\
1.7,2.4,3.5) \\
\end{array}$ & $\begin{array}{l}(4.75,5.25,5.75 ; \\
4.25,5.25,6.75)\end{array}$ \\
\hline
\end{tabular}

Table 3. Triangular intuitionistic fuzzy outputs in stage II assumed for $12 \mathrm{DMUs}$

\begin{tabular}{|c|c|c|c|}
\hline DMUs & Output 1 & Output 2 & Output 3 \\
\hline \multirow{2}{*}{1} & $(4,4.5,5 ;$ & $(4.18,4.68,5.18 ;$ & $(3.3,3.8,4.3 ;$ \\
& $3.5,4.5,6)$ & $3.68,4.68,6.18)$ & $2.8,3.8,5.3)$ \\
\hline \multirow{2}{*}{2} & $(3.53,4.03,4.53 ;$ & $(3.88,4.38,4.88 ;$ & $(3.36,3.86,4.36 ;$ \\
& $3.03,4.03,5.53)$ & $3.38,4.38,5.88)$ & $2.86,3.86,5.36)$ \\
\hline \multirow{2}{*}{3} & $(3.57,4.07,4.57 ;$ & $(3.88,4.38,4.88 ;$ & $(3.49,3.99,4.49 ;$ \\
& $3.07,4.07,5.57)$ & $3.38,4.38,5.88)$ & $2.99,3.99,5.49)$ \\
\hline \multirow{2}{*}{4} & $(5,5.5,6 ;$ & $(4.87,5.37,5.87 ;$ & $(4.62,5.12,5.62 ;$ \\
& $4.5,5.5,7)$ & $4.37,5.37,6.87)$ & $4.12,5.12,6.62)$ \\
\hline \multirow{2}{*}{5} & $(3.32,3.82,4.32 ;$ & $(3.03,3.53,4.03 ;$ & $(3.1,3.6,4.1 ;$ \\
& $2.82,3.82,5.32)$ & $2.53,3.53,5.03)$ & $2.6,3.6,5.1)$ \\
\hline \multirow{2}{*}{6} & $(3.38,3.88,4.38 ;$ & $(3.14,3.64,4.14 ;$ & $(3.39,3.89,4.39 ;$ \\
& $2.88,3.88,5.38)$ & $2.64,3.64,5.14)$ & $2.89,3.89,5.39)$ \\
\hline \multirow{2}{*}{7} & $(3.27,3.77,4.27 ;$ & $(3.47,3.97,4.47 ;$ & $(3.65,4.15,4.65 ;$ \\
& $2.77,3.77,5.27)$ & $2.97,3.97,5.47)$ & $3.15,4.15,5.65)$ \\
\hline \multirow{2}{*}{8} & $(4.78,5.28,5.78 ;$ & $(5.1,5.6,6.1 ;$ & $(5.19,5.69,6.19 ;$ \\
& $4.28,5.28,6.78)$ & $4.6,5.6,7.1)$ & $4.69,5.69,7.19)$ \\
\hline \multirow{2}{*}{9} & $(3.91,4.41,4.91 ;$ & $(3.89,4.39,4.89 ;$ & $(3.7,4.2,4.7 ;$ \\
& $3.41,4.41,5.91)$ & $3.39,4.39,5.89)$ & $3.2,4.2,5.7)$ \\
\hline \multirow{2}{*}{10} & $(3.78,4.28,4.78 ;$ & $(4.04,4.54,5.04 ;$ & $(3.77,4.27,4.77 ;$ \\
& $3.28,4.28,5.78)$ & $3.54,4.54,6.04)$ & $3.27,4.27,5.77)$ \\
\hline \multirow{2}{*}{11} & $(3.41,3.91,4.41 ;$ & $(3.45,3.95,4.45 ;$ & $(2.98,3.48,3.98 ;$ \\
& $2.91,3.91,5.41)$ & $2.95,3.95,5.45)$ & $2.48,3.48,4.98)$ \\
\hline \multirow{2}{*}{12} & $(3.6,4.1,4.6 ;$ & $(3.89,4.39,4.89 ;$ & $(3.9,4.4,4.9 ;$ \\
& $3.1,4.1,5.6)$ & $3.39,4.39,5.89)$ & $3.4,4.4,5.9)$ \\
\hline \multirow{2}{*}{1} & & & \\
& & &
\end{tabular}

Table 4 shows the efficiency of the first and second stages and the overall efficiency of $D M U \mathrm{~s}$, according to Model (14), which is solved by Lingo software and considered $w_{1}=w_{2}=0.5$ to solve model (14). 
Table 4. The overall efficiency and the efficiencies of the first and second stage

\begin{tabular}{|c|c|c|c|c|}
\hline$D M U$ & $E_{1}^{*}$ & $E_{2}^{*}$ & $\frac{1}{E_{1}^{*}}$ & $E^{*}$ \\
\hline 1 & 0.862 & 1.231 & 0.812 & 0.699 \\
\hline 2 & 0.995 & 1.229 & 0.814 & 0.814 \\
\hline 3 & 0.939 & 1.251 & 0.799 & 0.751 \\
\hline 4 & 1 & 1.189 & 0.841 & 0.841 \\
\hline 5 & 0.923 & 1.263 & 0.791 & 0.730 \\
\hline 6 & 0.889 & 1.233 & 0.810 & 0.721 \\
\hline 7 & 0.936 & 1.234 & 0.811 & 0.759 \\
\hline 8 & 0.923 & 1 & 1 & 0.923 \\
\hline 9 & 0.985 & 1.264 & 0.791 & 0.779 \\
\hline 10 & 0.803 & 1.041 & 0.960 & 0.771 \\
\hline 11 & 0.936 & 1 & 0.989 & 0.936 \\
\hline 12 & 0.868 & 1.033 & 0.968 & 0.840 \\
\hline
\end{tabular}

When the optimal solution of model (14) is $E_{1}^{*}=E_{2}^{*}=1$, the two-stages of the process have a single overall efficiency. Therefore, Model (14) correctly defines the efficient frontier of the two-stage production process. Hence, according to the results of the above table, for the first stage of the fourth $D M U$, the input can be reduced with a fixed output, and for the second stage of the eighth $D M U$, the output can be increased by with a fixed input. Therefore, for the other $D M U$ s, should be used to produce less inputs in the first stage and should be used to produce more outputs in the second stage, so can increase the efficiency of the overall system.

\section{Discussion and conclusion}

This study aims to develop a two-stage DEA model for efficiency measurement with intuitionistic fuzzy data so as to determine the minimum and maximum input and output levels of $D M U \mathrm{~s}$ based on the minimisation of $E_{1}^{*}$ values and maximisation of $E_{2}^{*}$ values. The proposed model is solved for a numerical example with $12 D M U \mathrm{~s}$, each with 3 inputs in the first stage, 2 intermediates, and 3 outputs in the second stage, using Lingo software.

The review of the research literature show that previous studies on tracing the causes of inefficiency in two-stage DEA problems considered the stages as independent processes. This approach assumes that each subunit competes with the other one and has its own unique efficiency and, ultimately, considers the average efficiency of the two stages as the overall efficiency score $[9,25]$. But if you ignore the intermediate measures, competition may cause the second stage to appear inefficient, as it has to work with the added 
inputs. This may result in the product of the efficiency scores of the two stages becoming an unrealistic value. Also, while a few studies used the theory of intuitionistic fuzzy sets in DEA $[15,43]$, no study has applied this theory to the two-stage DEA. The model proposed by Kao and Hwang [25], which is an NDEA model based on slack variables, offers incomplete assessment of units as it ignores the intermediate values. Also, in the model by Chen et al. [9], which is inspired by the model by Kao and Hwang [25] but uses CRS, the overall efficiency is obtained by weighted averaging of the efficiency scores of the two stages based on an additive approach. According to Despotis et al. [16] and Anandarao et al. [3], the multiplicative method of Kao and Hwang [25] and the additive method of Chen et al. [9] both use a decomposition approach, meaning that they first obtain the overall efficiency and then use decomposition approach to determine the efficiency of the individual stages. Since this efficiency measurement approach is erroneous, they used a composition approach for the simultaneous maximisation of the overall efficiency and the efficiency of the individual stages. In the modeling approach of this study, to ensure the efficiency of the first and second stages, as well as the system as a whole, first, each stage is evaluated individually, and then the efficiency values of the two stages are adjusted simultaneously, using the multiplicative method to obtain the overall efficiency score. In this model, the first stage is output-oriented, and the second stage is inputoriented. In other words, each stage optimises the intermediate measures that link the two stages together independently. So, a two-stage production process with intuitionistic fuzzy data is created to allow managers better examine the performance of DMUs and assess their overall efficiency based on the efficiency of the first and second stages with the intermediate measures taken into account.

The feature that distinguishes the proposed model from the other models is the ability to reduce the impact of less significant factors on the efficiency of $D M U$ s. This means that if a unit is inefficient, the model can show the more important stage in which the efficiency is undesirable, that is, the stage that needs to be improved. And if a unit has a good efficiency score, it means that the more important stage is consistent with the management goals. In other words, the proposed method takes into account not only input and output variables, but also intermediate measures and individual stages. Given the intuitionistic fuzzy nature of data in the proposed model, it can be expected to provide more accurate results than crisp models.

\section{References}

[1] AmERi Z., SANa S.S., SHeIKH R., Self-assessment of parallel network systems with intuitionistic fuzzy data: a case study, Soft. Comput., 2019, 1-12.

[2] AmIN G.R., Toloo M., Finding the most efficient DMUs in DEA: An improved integrated model, Comp. Ind. Eng., 2007, 52 (1), 71-77.

[3] ANANDARaO S., DURAi S.R.S., GoYARI P., Efficiency decomposition in two-stage data envelopment analysis: an application to life insurance companies in India, J. Quant. Econ., 2019, 17 (2), 271-285. 
[4] Atanassov K.T., On a second new generalization of the Fibonacci sequence, Fibon. Quart., 1986, 24 (4), 362-365.

[5] BAMAKAn S.M.H., GHOlami P., A novel feature selection method based on an integrated data envelopment analysis and entropy model, Proc. Comp. Sci., 2014, 31, 632-638.

[6] Boran F.E., GENÇ S., KURT M., AKAY D., A multi-criteria intuitionistic fuzzy group decision making for supplier selection with TOPSIS method, Expert. Syst. Appl., 2009, 36 (8), 11363-11368.

[7] Castelli A., Pesenti R., UKovich W., A classification of DEA models when the internal structure of the decision making units is considered, Ann. Oper. Res., 2008, 173, 207-235.

[8] Charnes A., COOPER W.W., RHOdes E., Measuring the efficiency of decision making units, Eur. J. Oper. Res., 1978, 2 (6), 429-444.

[9] CHEN Y., COOK W.D., Li N., ZHU J., Additive efficiency decomposition in two-stage DEA, Eur. J. Oper. Res., 2009, 196 (3), 1170-1176.

[10] Chen S.H., Ranking fuzzy numbers with maximizing set and minimizing set, Fuzzy Sets Syst., 1985, $17,113-129$.

[11] CHEN Y., ZHU J., Measuring information technology's indirect impact on firm performance, Inform. Technol. Manage., 2004, 5 (1), 9-22.

[12] Chen Y., Liang L., YANG F., ZhU J., Evaluation of information technology investment: a data envelopment analysis approach, Comp. Oper. Res., 2006, 33 (5), 1368-1379.

[13] Chilingerian J.A., Sherman H.D., Health-care applications: from hospitals to physicians, from productive efficiency to quality frontiers, Handbook on data envelopment analysis, Springer, 2004, 481-537.

[14] Cook W.D., Zhu J., Bi G., YAng F., Network DEA: Additive efficiency decomposition, Eur. J. Oper. Res., 2010, 207 (2), 1122-1129.

[15] Daneshyar RouYendegh B., The DEA and intuitionistic fuzzy TOPSIS approach to departments' performances: a pilot study, J. Appl. Math., 2011, 2011.

[16] Despotis D.K., Koronakos G., Sotiros D., Composition versus decomposition in two-stage network DEA: a reverse approach, J. Prod. Anal., 2016, 45 (1), 71-87.

[17] EmRouZneJAD A., YANG G.L., A survey and analysis of the first 40 years of scholarly literature in DEA: 1978-2016, Socio-Econ. Plan. Sci., 2018, 61, 4-8.

[18] FARE R., GrossKopf S., Intertemporal production frontiers with dynamic DEA, Kluwer Academic, Boston 1996.

[19] FÄre R., Grosskopf S., DEA Network, Socio-Econ. Plan. Sci., 2000, 34 (1), 35-49.

[20] FärE R., Measuring Farrell efficiency for a firm with intermediate inputs, Acad. Econ. Pap., 1991, 19 (2), 329-340.

[21] Farrell M.J., The measurement of productive efficiency, J. R. Stat. Soc. Ser. A, 1957, 120 (3), 253-281.

[22] GrZegorzewski P., Distances and orderings in a family of intuitionistic fuzzy numbers, EUSFLAT Conf., Warsaw, Poland, 2003.

[23] Guo P., TAnaka H., Fuzzy DEA: a perceptual evaluation method, Fuzzy Sets Syst., 2001, 119 (1), 149-160.

[24] KaO C., Efficiency decomposition in network data envelopment analysis: A relational model, Eur. J. Oper. Res., 2009, 192 (3), 949-962.

[25] KaO C., HwANG S.N., Efficiency decomposition in two-stage data envelopment analysis: An application to non-life insurance companies in Taiwan, Eur. J. Oper. Res., 2008, 185 (1), 418-429.

[26] KaO C., Efficiency decomposition for parallel production systems, J. Oper. Res. Soc., 2012, 63 (1), 64-71.

[27] Kaо C., Network data envelopment analysis: A review, Eur. J. Oper. Res., 2014, 239 (1), 1-16.

[28] Kao C., Liu S.T., Fuzzy efficiency measures in data envelopment analysis, Fuzzy Sets Syst., 2000, $113,427-437$. 
[29] KaO C., LiU S.T., Efficiencies of two-stage systems with fuzzy data, Fuzzy Sets Syst., 2011, 176, $20-35$.

[30] LEÓN T., LIERn V., RUIZ J.L., SiRVENT I., A fuzzy mathematical programming approach to the assessment of efficiency with DEA model, Fuzzy Sets Syst., 2003, 139 (2), 407-419.

[31] LEWIS H.F., SEXTON T.R., Network DEA: efficiency analysis of organizations with complex internal structure, Comp. Oper. Res., 2004, 31 (9), 1365-1410.

[32] Liang L., YANG F., COOK W.D., ZHU J., DEA models for supply chain efficiency evaluation, Ann. Oper. Res., 2006, 145, 35-49.

[33] Liang L., COOK W.D, ZHU J., DEA models for two-stage processes: Game approach and efficiency decomposition, Nav. Res. Log., 2008, 55, 643-653.

[34] Li Y., Chen Y., LiAng L., XIE J., DEA models for extended two-stage network structures, Omega, 2012, 40 (5), 611-618.

[35] LI D.F., CHEN G.H., HwANG Z.G., Linear programming method for multiattribute group decision making using IF sets, Inform. Sci., 2010, 180 (9), 1591-1609.

[36] LIM S., ZHU J., Primal-dual correspondence and frontier projections in two-stage network DEA models, Omega, 2019, 83, 236-248.

[37] LiU S.T., Restricting weight flexibility in fuzzy two-stage DEA, Comp. Ind. Eng., 2014, 74, 149-160.

[38] LiU J.S., Lu L.Y.Y., Lu W.M., Lin B.J.Y., A survey of DEA application, Omega, 2013, 41 (5), 893-902.

[39] LozAno S., Process efficiency of two-stage systems with fuzzy data, Fuzzy Sets Syst., 2014, 243, 36-49.

[40] Maghbouli M., Amirteimoori A., Kordrostami S., Two-stage network structures with undesirable outputs: A DEA based approach, Measure., 2014, 48, 109-118.

[41] MAHAPATRA G., ROY T., Reliability evaluation using triangular intuitionistic fuzzy numbers arithmetic operations, World Acad. Sci. Eng. Technol., 2009, 50, 574-581.

[42] Nosrat A., Sanei M., Payan A., Hossenzadeh-Lotfi F., RAzAvyan S.H., Using credibility theory to evaluatethe fuzzy two-stage DEA; sensitivityand stability analysis, J. Intell. Fuzzy Syst., 2019, 1-20.

[43] PURI J., YadAV S.P., Intuitionistic fuzzy data envelopment analysis: An application to the banking sector in India, Expert Syst., Appl., 2015, 42 (11), 4982-4998.

[44] SaAti S., Memariani A., Reducing weight flexibility in fuzzy DEA, Appl. Math. Comp., 2005, 161 (2), 611-622.

[45] Sengupta J.K., A fuzzy systems approach in data envelopment analysis, Comp. Math. Appl., 1992, 24 (8-9), 259-266.

[46] Shakouri B., Shureshjani Abbasi R., Daneshian B., Hosseinzadeh Lotfi F., A parametric method for ranking intuitionistic fuzzy numbers and its application to solve intuitionistic fuzzy network data envelopment analysis models, Complexity, 2020, 2020, 1-25.

[47] Shureshjani R.A., Foroughi A.A., Solving generalized fuzzy data envelopment analysis model: a parametric approach, Cent. Eur. J. Oper. Res., 2017, 25, 889-905.

[48] Tavana M., Khalili-Damghani K.A., New two-stage Stackelberg fuzzy data envelopment analysis model, Measure., 2014, 53, 277-296.

[49] Tone K., Tsutsui M., Network DEA: A slacks-based measure approach, Eur. J. Oper. Res., 2009, 197 (1), 243-252.

[50] TRIANTIS K., GIROD O., A mathematical programming approach for measuring technical efficiency in a fuzzy environment, J. Prod. Anal., 1998, 10 (1), 85-102.

[51] WANG Y.M., GREATBANKS R., YANG J.B., Interval efficiency assessment using data envelopment analysis, Fuzzy Sets Syst., 2005, 153 (3), 347-370.

[52] Wei G., ZhaO X., WANG H., An approach to multiple attribute group decision making with interval intuitionistic trapezoidal fuzzy information, Technol. Econ. Dev. Eco., 2012, 18 (2), 317-330.

[53] ZADEH L.A., Fuzzy sets, Inform. Control., 1965, 8 (3), 338-353.

[54] ZimMERMANN H.J., Applications of fuzzy set theory to mathematical programming, Inform. Sci., 1985, $36(1-2), 29-58$. 